\title{
Preoperative Sedation, Hemodynamic Stability during General Anesthesia and Improving Postoperative Pain: Pregabalin Is the Answer
}

\author{
Heba El-Hussiny, Huda Fahmy, Ayman Mohammad Eldemrdash \\ Department of Anesthesia, Aswan University Hospital, Aswan, Egypt \\ Email: aymaneldemrdash@yahoo.com,hfa73@yahoo.com, heba2elhussiny@gmail.com
}

How to cite this paper: El-Hussiny, H., Fahmy, H. and Eldemrdash, A.M. (2018) Preoperative Sedation, Hemodynamic Stability during General Anesthesia and Improving Postoperative Pain: Pregabalin Is the Answer. Open Journal of Anesthesiology, 8, 14-26.

https://doi.org/10.4236/ojanes.2018.81002

Received: November 9, 2017

Accepted: January 26, 2018

Published: January 29, 2018

Copyright $\odot 2018$ by authors and Scientific Research Publishing Inc. This work is licensed under the Creative Commons Attribution International License (CC BY 4.0).

http://creativecommons.org/licenses/by/4.0/

c) (i) Open Access

\begin{abstract}
Background: Tracheal intubation is a noxious stimulus that tends to provoke a marked sympathetic response which is potentially deleterious in some patients. Various methods have been used to minimize and attenuate these potentially harmful responses. Aim of the study: The present study compared the efficacy and safety of two different doses (150 mg and $300 \mathrm{mg}$ ) of oral pregabalin premedication on attenuation of the hemodynamic pressor response to airway instrumentation, perioperative hemodynamic stability, preoperative sedation, and postoperative pain reduction. Patients and methods: This prospective, observational study consisted of 60 adult patients scheduled for laparoscopic cholecystectomy. The patients were randomized into three groups of 20 patients each. Group I (P0) received an oral placebo, group II (P150) received $150 \mathrm{mg}$ of oral pregabalin and group III (P300) received $300 \mathrm{mg}$ of oral pregabalin $1 \mathrm{~h}$ prior to induction. All patients were assessed for pre-operative sedation, perioperative hemodynamic changes, Post-operative pain and analgesic consumption. Results: Regarding the efficacy of the preoperative administration of oral pregabalin, a dose dependent attenuation in the increased in heart rate, systolic, and diastolic blood pressure, and mean arterial blood pressure resulting from laryngoscopy and intubation was observed ( $300 \mathrm{mg}>150 \mathrm{mg}$ ), along with a subsequent decrease in intraoperative fentanyl supplementation. On anxiolysis, patients were more comfortable and asleep in the pregabalin groups as compared with the control group, in which more patients were awake and agitated. Post-operative pain and analgesic consumption were effectively reduced by (150 $\mathrm{mg}$ and $300 \mathrm{mg}$ ) pregabalin in a dose-dependent manner. Postoperative nausea and vomiting were significantly lower with the administration of pregabalin compared with the placebo group $(P<0.008)$. Additionally, pregabalin increased the incidence of dizziness and visual disturbances in a dose-dependent manner. Con-
\end{abstract}


clusion: Oral pregabalin premedication adequately sedated patients and attenuated the hemodynamic pressor response to airway instrumentation in a dose-dependent manner. Premedicated patients were haemodynamically stable perioperatively without recovery time prolongation or side effects, except dizziness with $300 \mathrm{mg}$ of oral pregabalin. Additionally, oral pregabalin reduced postoperative pain and analgesic consumption in a dose-dependent manner.

\section{Keywords}

Pregabalin, Premedication, Sedation, Postoperative Pain

\section{Introduction}

Endotracheal intubation is one of the most invasive stimuli in anesthesia, particularly during induction and after tracheal intubation. Laryngoscopy and tracheal intubation are an essential part of general anesthesia but severely noxious stimuli that induce an intense sympathetic hemodynamic response [1]. Tachycardia and hypertension cause an imbalance in myocardial oxygen supply and demand, predisposing patients to ischemia, infarction and heart failure. While this sympathetic response can normally be tolerated by healthy adults, it can be quite hazardous in patients with compromised cardiovascular function. The search for an ideal drug to attenuate the pressor response to intubation has been ongoing for several decades [2]. Appropriate premedication, smooth induction and rapid intubation would prevent the associated risks and complications of the hemodynamic pressor responses, which may be attenuated pharmacologically. Various pharmacological techniques have been evaluated either as premedication or during induction to attenuate the adverse hemodynamic response to laryngoscopy and tracheal intubation, including deepening the anesthesia and, pretreatment with opioids, (beta) blockers, vasodilators and calcium channel blockers but with variable results [3].

Recently, gamma-amino butyric acid (GABA) analogs pregabalin and gabapentin have gained prominence in various clinical studies, as they can not only alleviate perioperative pain but also effectively attenuate the pressor response to intubation and produce perioperative sedation and anxiolysis.

Gabapentin was introduced as an antiepileptic drug in 1993. The most recent studies aiming to attenuate the hemodynamic response to laryngoscopy and intubation have focused on the effect of gabapentin [4]. Pregabalin is a lipophilic gamma-amino-butyric acid (GABA) analog, that is, absorbed and tolerated well after oral administration, with limited side effects. It has no known clinically relevant drug interactions. Pregabalin undergoes negligible hepatic metabolism and is eliminated by renal excretion. It has been alleged to possess anxiolytic, analgesic, and anticonvulsant properties. Recent studies have found that premedication with oral pregabalin could produce dose-dependent reductions in acute 
(state) anxiety and increases in sedation (sleepiness) before the induction of general anesthesia; however few studies on the cardiovascular properties of pregabalin in patients undergoing surgery are present in the literature [5] [6]. Thus, this study compared the efficacy and safety of two different doses (150 mg and $300 \mathrm{mg}$ respectively) of oral pregabalin premedication on attenuation of the hemodynamic pressor response to airway instrumentation and, perioperative hemodynamic stability, as well as secondary outcomes, i.e., preoperative sedation, acute postoperative pain and analgesics consumption, in patients undergoing laparoscopic cholecystectomy. The effect of pregabalin on the hemodynamic response to laryngoscopy and intubation may be explained by its inhibitory effects on membrane voltage-gated calcium channels. Pregabalin binds potently and selectively to the alpha 2 delta subunit of hyper excited voltage-gated calcium channels and inhibits the release of several neurotransmitters, such as glutamate, noradrenaline, and substance $\mathrm{P}$ [7]. It does not interact with GABA receptors. However, few data are available in the literature regarding the effect of pregabalin on the cardiovascular system. Pain after surgery has a neuropathic component as well as somatic and visceral characteristics, and agents that are effective in the treatment of neuropathic pain are effective in reducing central sensitization [8]. The efficacy of oral pregabalin in providing postoperative analgesia and reducing parenteral analgesic use has been demonstrated in several studies [9].

\section{Patients and Methods}

Approval was obtained from the local ethics committee, and written informed consent was obtained from each patient in this prospective, observational study consisting of 60 adult patients scheduled for laparoscopic cholecystectomy in Aswan University Hospital from October 2015 to October 2016. Inclusion criteria: Age between 20 and 60, both genders, ASA physical status I and II, and airway: Mallampatti Grade I and II for orotracheal intubation only. Exclusion criteria: History of allergy to pregabalin, anticipated difficult intubation, laryngoscopy exceeding $20 \mathrm{~s}$ with normal airway, second attempt for intubation in normal airway, and patients on sedatives, hypnotics, and analgesics for chronic pain.

Patients were randomly allocated to one of three groups of 20 patients each by a computer-generated random table. Group allocations were performed by an anesthetist who was unaware of the study protocol.

- Group I received a placebo (P0).

- Group II received $150 \mathrm{mg}$ pregabalin (P150).

- Group III received $300 \mathrm{mg}$ pregabalin (P300). The placebo and pregabalin were administrated orally with sips of water approximately $1 \mathrm{~h}$ before the induction of general anesthesia.

The level of sedation was assessed using the Ramsay sedation scale (RSS) done premedication, at $1 \mathrm{~h}$ after medication, during postoperative recovery, and $2 \mathrm{~h}, 4$ $\mathrm{h}, 6 \mathrm{~h}$ and $24 \mathrm{~h}$ thereafter. 
1) Anxious, agitated or restless.

2) Co-operative, oriented and tranquil.

3) Responds to command.

4) Asleep with brisk response to stimulus.

5) Asleep with sluggish response to stimulus.

6) Asleep with no response.

On arrival to the operating room, monitors were attached. Baseline heart rate (HR), systolic blood pressures (SBP), diastolic blood pressures (DBP) and mean arterial blood pressures (MBP) were recorded. After pre-oxygenation for $3 \mathrm{~min}$ with $100 \%$ oxygen, anesthesia was induced with Propofol at $(2 \mathrm{mg} / \mathrm{kg})$ or dose sufficient for the loss of verbal commands. The direct laryngoscopy and intubation was facilitated with atracurium at $0.5 \mathrm{mg} / \mathrm{kg}$. Anesthesia was maintained with isoflurane in $40 \%$ air and $60 \%$ oxygen. The patients were mechanically ventilated to maintain normocapnia $\left(\mathrm{CO}_{2}\right.$ between 35 and $\left.40 \mathrm{mmHg}\right)$. The supplemental neuromuscular blockade was achieved with atracurium at $0.1 \mathrm{mg} / \mathrm{kg}$. After completion of the surgery, residual neuromuscular block was antagonized with appropriate doses of neostigmine $(0.05 \mathrm{mg} / \mathrm{kg})$ and atropine $(0.01 \mathrm{mg} / \mathrm{kg})$, and extubation was performed when respiration was adequate.

Intraoperative $\mathrm{HR}, \mathrm{SBP}, \mathrm{DBP}, \mathrm{MAP}$, electrocardiography, and pulse oximeter $\left(\mathrm{SpO}_{2}\right)$ and $\mathrm{EtCO}_{2}$ levels were continuously monitored until the end of the surgery using a VESTA 2000 system. Hemodynamic changes [after premedication], [after induction], [during laryngoscopy] and at (1) (3) (5) (10) (30) and (60) min. after intubation were recorded.

If the HR increased to 100 beats/min or SBP increased to more than 160 $\mathrm{mmHg}$, the patient was treated with an increased concentration of inhaled isoflurane and supplemental bolus doses of fentanyl $(0.5 \mu \mathrm{g} / \mathrm{kg})$.

The patients were transferred to the post-anesthesia care unit (PACU) and monitored for vital signs, postoperative pain intensity using the Verbal Numerical Rating Scale (VNRS) and any side effects such as nausea, vomiting or any respiratory inadequacy [at recovery time], $(2 \mathrm{~h}),(4 \mathrm{~h}),(6 \mathrm{~h})$ and $(24 \mathrm{~h})$ postoperatively. If any side-effects were noted, they were treated accordingly. All patients received $1 \mathrm{gm}$ of Paracetamol by infusion at the PACU. Then, patients received analgesia as follows according to the VNRS score when VNRS $\geq 4$ postoperative (whether achieved during rest or movement):

1) Ketorolac $30 \mathrm{mg}$, I.V.: $4 \leq \mathrm{VNRS} \leq 6$ (moderate pain score)

2) Morphine $0.1 \mathrm{mg} / \mathrm{kg}$, I.V.: $7 \leq \mathrm{VNRS} \leq 10$ (severe pain score)

\section{Statistical analysis:}

Date entry and data analysis were done using SPSS version 23 (Statistical Package for Social Science). Data were presented as number, percentage, mean, standard deviation. Chi-square test and Fisher Exact test were used to compare between qualitative variables. Mann Whitney was used to compare quantitative variables between groups. As regard using paired T-test to comparison between baseline and each time in the same group. P-value considered statistically signif- 
icant when $P<0.05$.

\section{Results}

Sixty patients were scheduled for laparoscopic cholecystectomy at Aswan University Hospital. Patients were randomly allocated to one of three groups of 20 patients each. Table 1 shows the demographic data of the study groups, with non-significance differences $(P>0.05)$ in age, sex and weight between the groups.

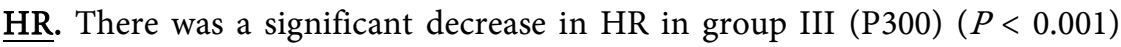
during laryngoscopy compared with the placebo group (P0). At $10 \mathrm{~min}, 30 \mathrm{~min}$ and 1 hour after intubation, HR remained significantly attenuated in the premedicated groups, compared with the placebo group (P0).

At recovery and 2, 4 and $6 \mathrm{~h}$ postoperatively, HR remained significantly attenuated in the premedictated groups compared with the placebo group (P0), while after $24 \mathrm{~h}$ HR remained significantly attenuated $(P<0.04)$ in group III (P300) only compared with the placebo group (P0) (Figure 1).

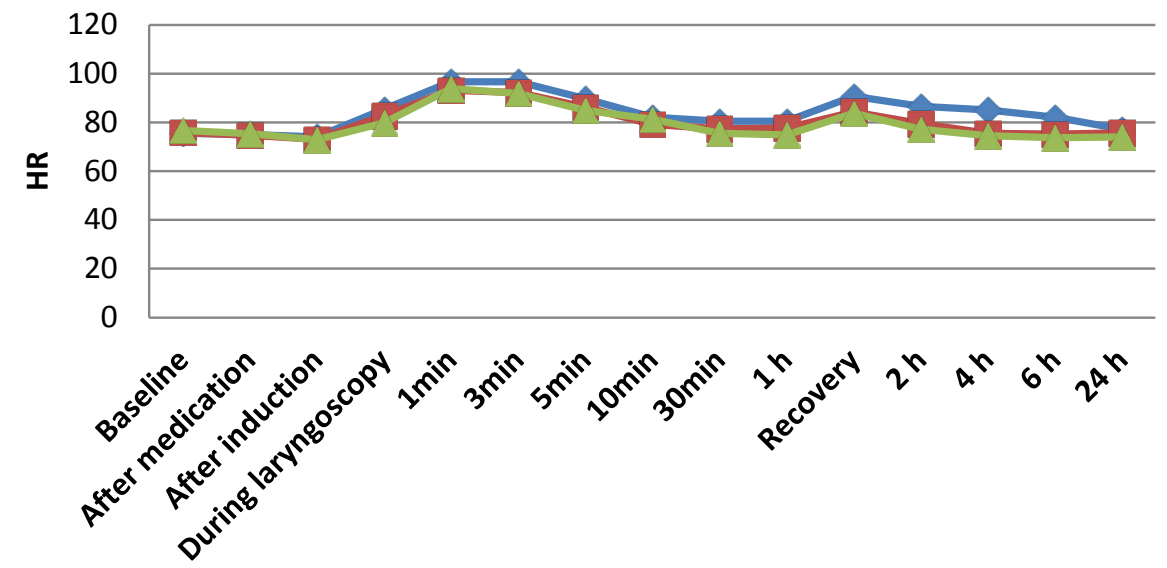

Figure 1. Heart Rate in study groups.

Table 1. Demographic data of the study groups.

\begin{tabular}{cccc}
\hline Item & $\begin{array}{c}\text { Group I } \\
(\text { P0 })\end{array}$ & $\begin{array}{c}\text { Group II } \\
(\text { P150) }\end{array}$ & $\begin{array}{c}\text { Group III } \\
(\text { P300 })\end{array}$ \\
\hline 1) Age "years" & & & \\
Mean \pm SD & $40.8 \pm 9.74$ & $37.85 \pm 11.1$ & $39.9 \pm 9.50$ \\
$($ min - max $)$ & $(21.0-60.0)$ & $(21.0-58.0)$ & $(21.0-56.0)$ \\
2) Sex: & & & $5(25.0 \%)$ \\
Male & $9(45.0 \%)$ & $6(30.0 \%)$ & $15(75.0 \%)$ \\
Female & $11(55.0 \%)$ & $14(70.0 \%)$ & $88.5 \pm 15.53$ \\
3) Weight "kg": & & & $(65.0-120.0)$ \\
Mean \pm SD & $81.1 \pm 14.46$ & $88.5 \pm 15.53$ & \\
(min - max $)$ & $(59.0-112.0)$ & $(65.0-120.0)$ & \\
\hline
\end{tabular}


SBP. SBP, was significantly lower in group II compared with group I during laryngoscopy and after intubation from $1 \mathrm{~min}$ to $1 \mathrm{hr}$. SBP was significantly lower in group III compared with group II after medication, and at $1 \mathrm{~min}, 5 \mathrm{~min}$ and 10 min after intubation (Figure 2).

DBP. DBP, was significantly lower in group II compared with group I during laryngoscopy and after intubation from 1 to $5 \mathrm{~min}$. DBP was significantly reduced in group III compared with group II after general anesthesia induction and during laryngoscopy (Figure 3).

MAP. The MAP in the study groups, was significantly attenuated in the premedicated groups compared with the baseline values, in a dose-dependent manner (Figure 3).

The MAP values were attenuated during laryngoscopy and after intubation, in the premedicated groups compared with the placebo group.

Even in the PACU, cardiovascular parameters remained at a lower level in the pregabalin groups in a dose-dependent manner than in the placebo group (Figure 4).

RSS sedation level. There were non-significant differences $(P>0.05)$ in the premedication RSS level of sedation between the study groups but highly significant differences $(P<0.001)$ at $1 \mathrm{~h}$. postmedication were observed between the study groups. Clear increases in RSS score were observed in groups II (P150) and

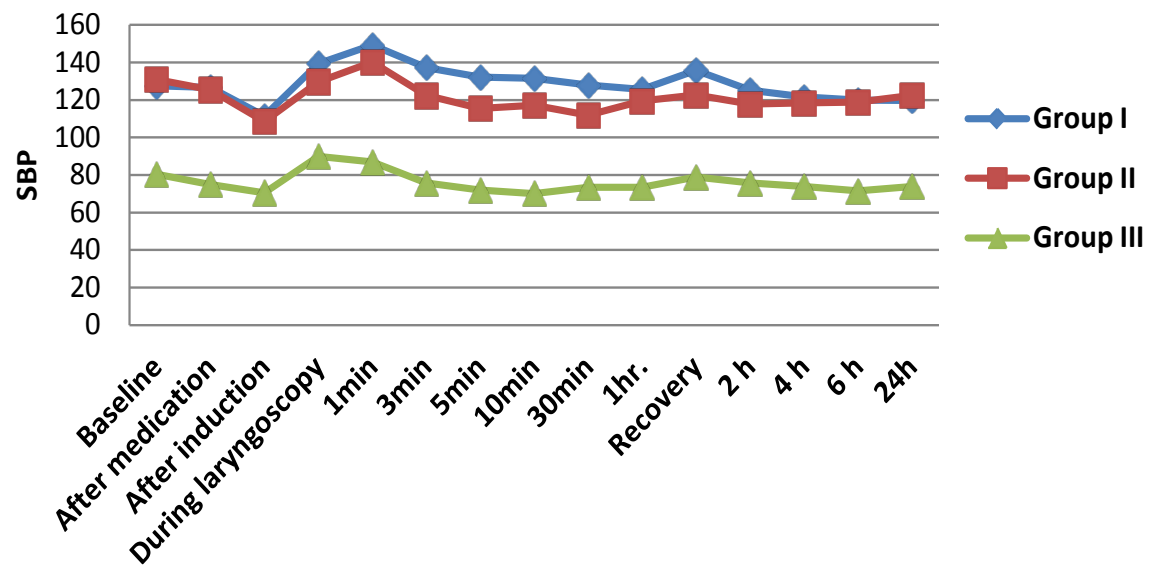

Figure 2. Systolic blood pressure in study groups.

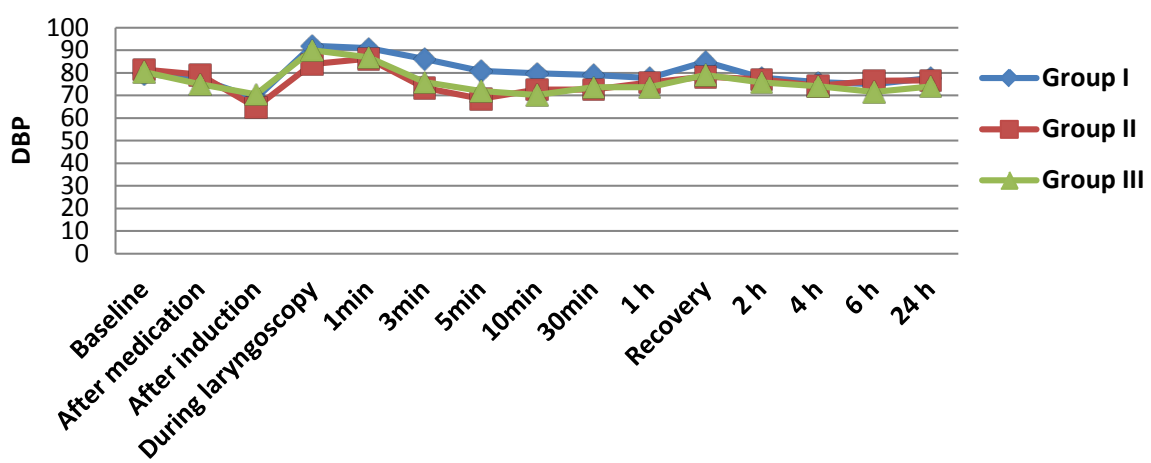

Figure 3. Diastolic blood pressure in study groups. 


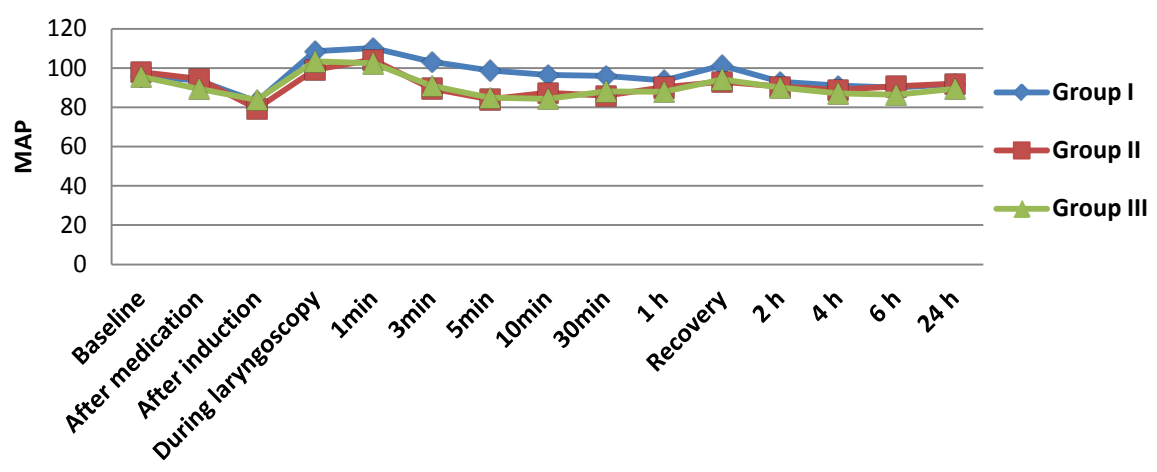

Figure 4. Mean arterial pressure in study groups.

III (P300) compared with the baseline values $(P=0.002)$. The degree of sedation was significantly higher in group III (P300) than in group II (P150) compared with group I (P0).

Analysis of the postoperative sedation scores, showed that the degree of sedation was significantly higher in group III (P300) than in group II (P150) compared with group I (P0) at all postoperative time points $(P<0.001)$ (Figure 5).

Postoperative pain. Comparison of static (Figure 6) and dynamic (Figure 7) postoperative pain showed significantly reduction in the pregabalin groups $(P<$ 0.001 ) compared with the placebo group from recovery to $24 \mathrm{~h}$.

Analgesic consumption. A significant increase $(P<0.05)$ in intraoperative fentanyl consumption was observed in the placebo group (Figure 8). There was a significant increase in postoperative ketorolac consumption in group I compared with group II and group III. Additionally, there was a highly significant increase in postoperative morphine consumption in group I compared with groups II and III (Figure 8).

Side effects. A highly significant incidence $(P<0.008)$ of nausea and vomiting were observed in the placebo group (Figure 9) while a significant incidence of dizziness $(P<0.000)$ was observed in group III (P 300) (Figure 10). A comparison of the postoperative side effects observed in the study groups is showing in (Figure 10).

\section{Discussion}

Pregabalin possesses several properties render it a valuable premedicant for attenuating the hemodynamic response to laryngoscopy and intubation and it is alleged to modulate the release of excitatory neurotransmitters, leading to reduced levels of anxiety and pain [10].

The haemodynamic pressor response to laryngoscopy and intubation, in the form of tachycardia and hypertension, occurs frequently [11]. Shribman et al. reported that induction by laryngoscopye alone or tracheal intubation increases the arterial blood pressure and catecholamine levels, but intubation considerably increases the HR [12]. Reid et al. and Hassan et al. reported high incidences of myocardial ischemia, cardiac arrhythmias, acute left ventricular failure and cerebrovascular accidents after intubation in hypertensive patients [12] [13] [14]. 


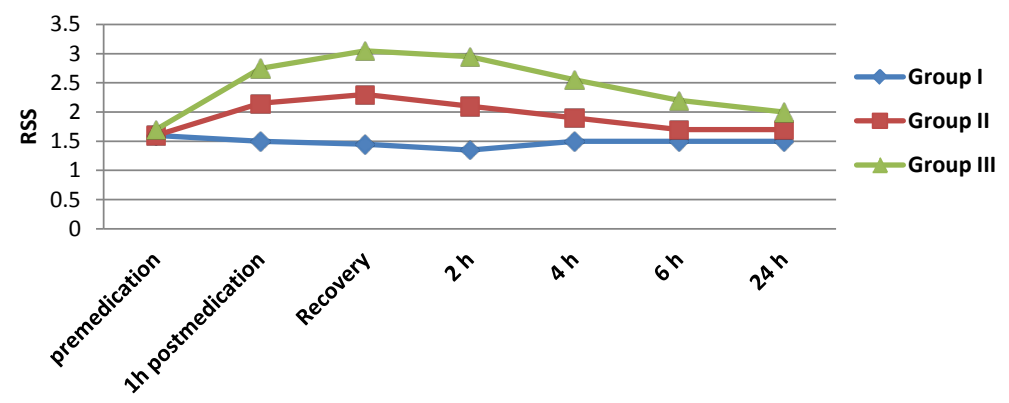

Figure 5. The level of sedation "Ramsay sedation scale" in study groups.

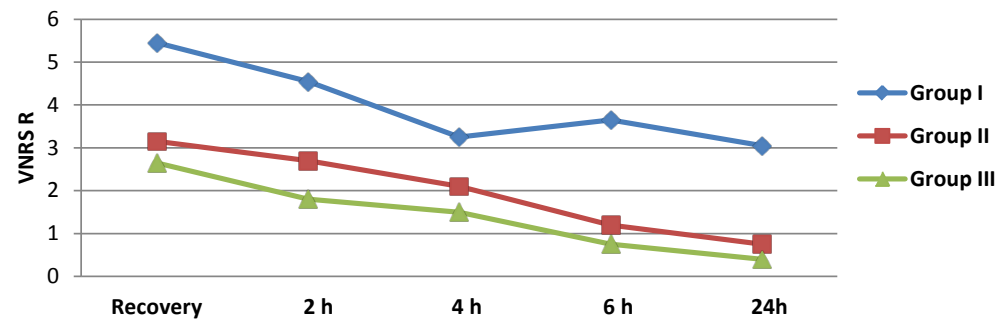

Figure 6. The level of (VNRS R) at rest in study groups.

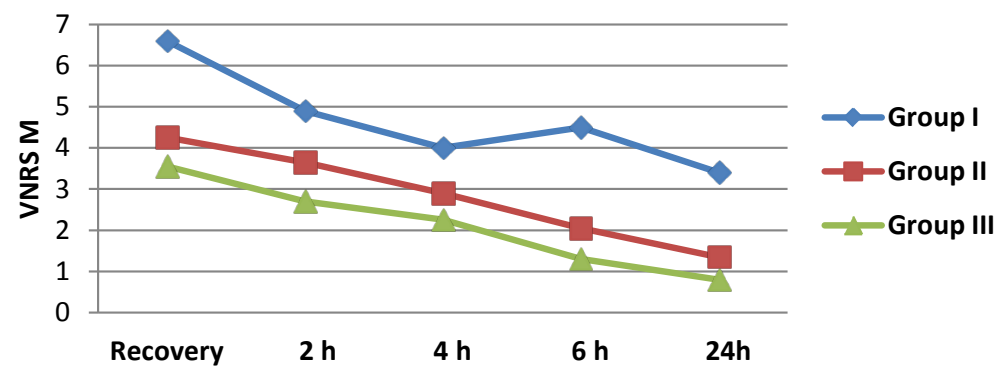

Figure 7. The level of (VNRS M) at movement in study groups.

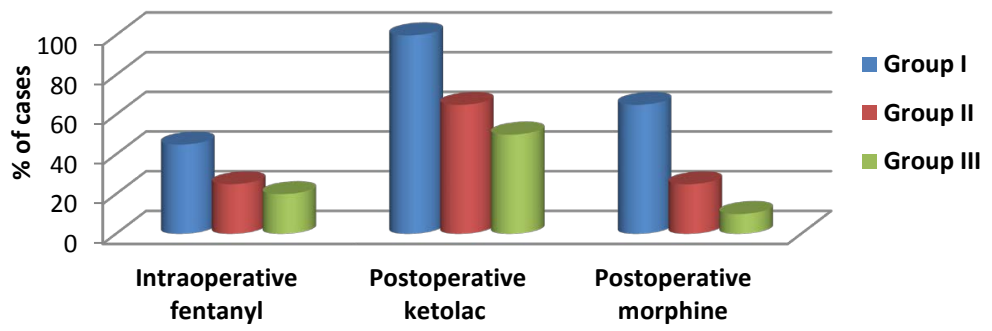

Figure 8. Comparison between analgesic consumption in study groups.

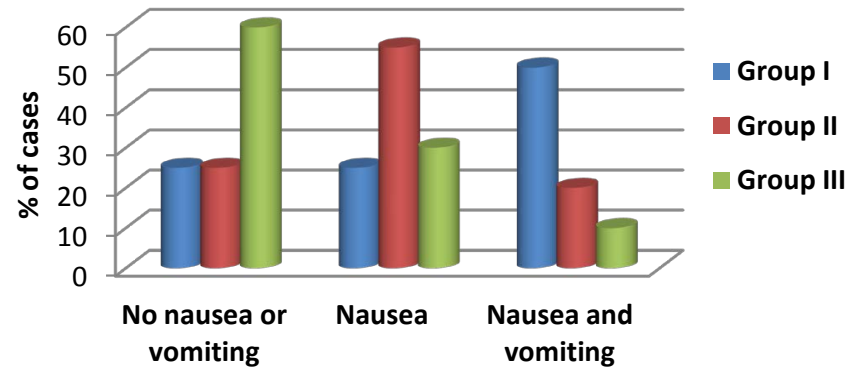

Figure 9. Comparison between nausea, vomiting in study groups. 


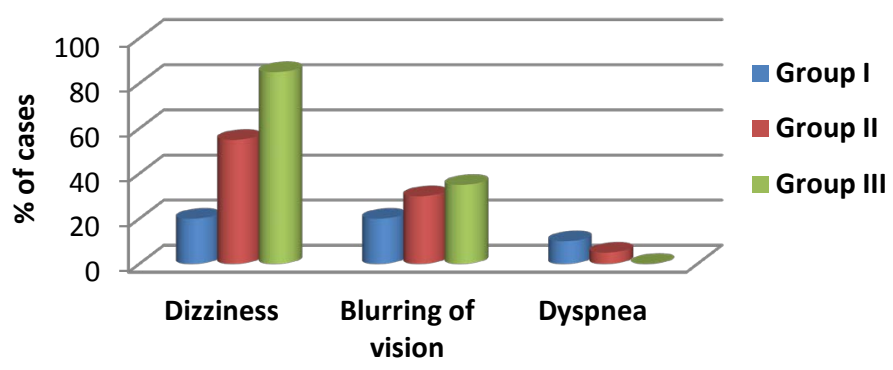

Figure 10. Comparison between side effect postoperative in study groups.

In this study, during laryngoscopy there was a significant increase in HR in group I compared with groups II and III. Then, after intubation it was significantly increased in all the three groups, with a maximum increase at $1 \mathrm{~min}$ after intubation. This significant increase lasted for a longer duration in group I, up to $30 \mathrm{~min}$ after intubation, than in group II and III up to $5 \mathrm{~min}$ after intubation, meanings that the response to laryngoscopy and intubation was very much exaggerated in group I, with non-significant increases in HR in group II compared with group III.

Although the HR increase was not completely attenuated by pregabalin, the drug obviously mitigated the HR after laryngoscopy and intubation, which is in agreement with findings reported by Meena et al. showing no significant difference in the HR before and after premedication [15]. Immediately after laryngoscopy and intubation, the HR increased significantly in all groups, but the increase was smallest in group III (PG300); as such, the heart HR was not completely attenuated by pregabalin but was definitely mitigated after laryngoscopy. Similarly, Rastogi et al. studied the effect of different doses of pregabalin premedication for attenuating the hemodynamic pressor response to airway instrumentation during general anesthesia [16]. They reported that the HR increased significantly immediately after laryngoscopy and intubation in all groups. However, the increase was the smallest with $150 \mathrm{mg}$ of pregabalin. In contrast, Gupta et al. found no significant difference in HR between the placebo group and the group administrated $150 \mathrm{mg}$ of pregabalin; in addition, they found no statistically significant HR attenuation in the pregabalin premedicated groups, with a maximal increase in HR at $1 \mathrm{~min}$ after intubation and the smallest increase in pregabalin group, but this relation to group I was statistically insignificant [3].

In our study, The MAP in the study groups, was significantly attenuated in the premedicated groups compared with the baseline values, in a dose-dependent manner. The MAP values were attenuated during laryngoscopy and after intubation, in the premedicated groups compared with the placebo group.

The results of the current study are in agreement with those of studies performed by Singh and Arora [17], Montazeri et al. [18] and Rastogi et al. [16], who demonstrated that the hemodynamic pressor response to airway instrumentation was attenuated by the use of oral pregabalin as a premedication. Similar results have also been reported by Salman et al. [7] and Eren et al. [19] who observed the a significant increase in HR and BP in the control group and atte- 
nuated BP the group premedicated with $150 \mathrm{mg}$ of pregabalin after laryngoscopy and intubation.

Preoperative anxiety remains a problem for many patients during the perioperative period. A high degree of anxiety increases the difficulty of controlling postoperative pain. At most centers, patients normally receive sedatives to decrease anxiety before surgery. One study concluded that benzodiazepine premedication had low beneficial effects on the postoperative clinical course of women undergoing abdominal hysterectomy [12].

The focus on perioperative sedation in our study includes the whole spectrum of anxiety, amnesia and hypnosis. Sedation was assessed with RSS and highly significance difference were observed between the study groups at $1 \mathrm{hr}$. postmedication and postoperatively at all-time points.

Comparing group I with groups II \& III, there was a more significant increase in the incidence of sedation between group I and III than between group I and II, meanings that the risk of perioperative sedation is dependent on the dose of preoperative pregabalin administrated. This finding is in agreement with those of White et al. [9], who in their dose-ranging study on pregabalin addressed sedation itself as the primary end-point and found that preoperative pregabalin administration (75 - $100-150-300 \mathrm{mg}$ ) increased perioperative sedation in a dose-dependent manner. In contrast, Agraweel et al., used preoperative pregabalin at dose of $150 \mathrm{mg}$ and reported no significant difference in RSS score [20]. The same applies to data reported by Peng et al., who assessed such side effects with the use of lower pregabalin doses (50 and $75 \mathrm{mg}$ ) [21].

In this study, tachycardia was defined as HR greater than 100 beats/min and hypertension was defined as a SBP greater than $160 \mathrm{mmHg}$; these conditions were treated by supplemental bolus doses of fentanyl $(0.5 \mu \mathrm{g} / \mathrm{kg})$. There was a non-significant difference between groups II and III in intraoperative fentanyl consumption but, there was a moderately significant reduction in groups II and III compared with group I. These results are in agreement with those of Bahgat et al., whose study showed that the preoperative administration of $300 \mathrm{mg}$ of oral pregabalin significantly reduces the intraoperative fentanyl requirements and end-tidal isoflurane concentrations required to maintain adequate anesthesia [22].

The results of this study showed that single preoperative oral dose of pregabalin (150 mg or $300 \mathrm{mg}$ ) effectively reduced the postoperative pain in dose-dependent manner. Another study conducted by Pang et al., to test low dose pregabalin (75, $150 \mathrm{mg}$ ) showed a significant reduction in postoperative pain intensity, as assessed by verbal rating score (VRS) [21]. Peach et al., found that a single preoperative dose of $100 \mathrm{mg}$ of pregabalin does not reduce acute pain or improve recovery after minor gynecological surgeries, such as dilatation and curettage [23]. Siddiqui et al., examined the effect of a single preoperative oral dose of pregabalin $(150 \mathrm{mg})$ in patients with irritable bowel disease undergoing major bowel surgery, and the results suggested that there was no reduction in the postoperative pain scores, or opioid consumption [24]. 
In our study ketorolac and morphine consumption was significantly reduced in groups II and III compared with group I but there were no significant difference between groups II and III, indicating that preoperative pregabalin reduces postoperative analgesic consumption and that the dose of $150 \mathrm{mg}$ is effective for this purpose. This finding agrees with those of Park et al., who found that fewer ketorolac injections were required in the pregabalin group than in the control group, but that the difference between the groups was not significant [25].

In this study, the incidence of postoperative vomiting was significantly lower with the use of pregabalin, which might be related to the decreased use of opioids after surgery and the consequent decrease in adverse opioid-related effects [26]. Other side effects analyzed in our study were dizziness, blurred vision and dyspnea occurring during the first $24 \mathrm{~h}$ after surgery. There was a highly significant increase in the incidence of dizziness among the three study groups. There was significant increase in the incidence of dizziness in groups II and III compared with group I and in group III compared with group II. Therefore, the incidence of dizziness increases with pregabalin administration in a dose- dependent manner.

\section{Conclusion}

The haemodynamic pressor response was significantly attenuated by oral pregabalin premedication in a dose-dependent manner, with a minimum effect on HR.

\section{References}

[1] Kaymak, C., Kocabas, N.A., Durmaz, E. and Oztuna, D. (2006) Adrenoceptor (ADRB2) Pharmacogenetics and Cardiovascular Phenotypes during Laryngoscopy and Tracheal Intubation. International Journal of Toxicology, 25, 443-449. https://doi.org/10.1080/10915810600959519

[2] Korpien, R., Sarnivaara, L., Siren, K. and Sarna, S. (1995) Modification of the Haemodynamic Response to Induction of Anaesthesia and Tracheal Intubation with Alfentanil, Esmolol and Their Combination. Canadian Journal of Anesthesia, 42, 298-304. https://doi.org/10.1007/BF03010706

[3] Gupta, K., Bansal, P., Prashant, K. and Singh, Y.P. (2011) Pregabalin Premedication-A New Treatment Option for Hemodynamic Stability during General Anesthesia: A Prospective Study. Anesthesia: Essays and Researches, 5, 57-62. https://doi.org/10.4103/0259-1162.84192

[4] Raouf Ali, A., El Gohary, M., et al. (2009) Efficacy of Preoperative Oral Gabapentin in Attenuation of Neuro-Endocrine Response to Laryngoscopy and Endotracheal Intubation. Journal of Medical Science, 9, 24-29.

https://doi.org/10.3923/jms.2009.24.29

[5] Izyaslav, L. (2001) Phenibut ( $\beta$-Phenyl-GABA): A Tranquilizer and Nootropic Drug. CNS Drug Reviews, 7, 471-481.

[6] Rastogi, B., Gupta, K. and Gupta, P.K. (2012) Oral Pregabalin Premedication for Attenuation of Haemodynamic Pressor Response of Airway Instrumentation during General Anaesthesia: A Dose Response Study. Indian Journal of Anaesthesia, 56, 49-54. https://doi.org/10.4103/0019-5049.93344 
[7] Salman, E., Çelik, Ç. and Candan, S. (2012) Premedication with Single Dose Pregabalin $150 \mathrm{mg}$ Attenuates Hemodynamic Response to Laryngoscopy and Endotracheal Intubation. Scientific Reports, 47, 34-41.

[8] Woolf, C.J. (2011) Central Sensitization: Implicationsor the Diagnosis and Treatment of Pain. Pain, 152, 2-15. https://doi.org/10.1016/j.pain.2010.09.030

[9] White, P.F., Tufanogullari, B., Taylor, J. and Klein, K. (2009) The Effect of Pregabalin on Preoperative Anxiety and Sedation Levels: A Dose Ranging Study. Anesthesia \& Analgesia, 108, 1140-1145. https://doi.org/10.1213/ane.0b013e31818d40ce

[10] Kavoussi, R. (2006) Pregabalin: From Molecule to Medicine. European Neuropsychopharmacology, 16, S128-S133. https://doi.org/10.1016/j.euroneuro.2006.04.005

[11] Malde, A.D. and Sarode, V. (2007) Attenuation of the Hemodynamic Response to Endotracheal Intubation: Fentanyl versus Lignocaine. International Journal of Clinical Anesthesiology, 12, 1-13.

[12] Shribman, A.J., Smith, G. and Achola, K.J. (1987) Cardiovascular and Catecholamine Response to Laryngoscopy with and without Tracheal Intubation. British Journal of Anaesthesia, 59, 295-299. https://doi.org/10.1093/bja/59.3.295

[13] Reid, L.C. and Brace, D.E. (1940) Irritation of the Respiratory Tract and Its Reflex Effect upon Heart. Surgery, Gynecology \& Obstetrics, 70, 157-162.

[14] Hassan, H.G., El- Sharkawy, T.Y., Renk, H., Mansour, G. and Fouda, A. (1991) Hemodynamic and Catecholamine Stress Responses to Laryngoscopy with vs without Endotracheal Intubation. Acta Anaesthesiologica Scandinavica, 35, 442-447. https://doi.org/10.1111/j.1399-6576.1991.tb03325.x

[15] Meena, R., Meena, K. and Prakash, S. (2016) Study of Attenuation of Cardiovascular Response during Laryngoscopy and Intubation Using Two Different Doses of Pregabalin as Premedication in Controlled Hypertensive Patients-A RCT. Journal of Anesthesia and Clinical Research, 7, 607. https://doi.org/10.4172/2155-6148.1000607

[16] Rastogi, B., Gupta, K., Gupta, P.K., Agarwal, S., Jain, M., et al. (2012) Oral Pregabalin Premedication for Attenuation of Haemodynamic Pressor Response of Airway Instrumentation during General Anaesthesia: A Dose Response Study. Indian Journal of Anaesthesia, 56, 49-54. https://doi.org/10.4103/0019-5049.93344

[17] Singh, S. and Arora, K. (2011) Effect of Oral Clonidine Premedication on Perioperative Haemodynamic Response and Postoperative Analgesic Requirement for $\mathrm{Pa}$ tients Undergoing Laparoscopic Cholecystectomy. Indian Journal of Anaesthesia, 55, 26-30. https://doi.org/10.4103/0019-5049.76583

[18] Montazeri, K., Kashefi, P., Honarmand, A., Safavi, M. and Hirmanpour, A. (2011) Attenuation of the Pressor Response to Direct Laryngoscopy and Tracheal Intubation: Oral Clonidine vs. Oral Gabapentin Premedication. Journal of Research in Medical Sciences, 16, 377-386.

[19] Eren, G., Kozanhan, B. and Hergunsel, O. (2009) Pregabalin Blunts Cardiovascular Responses to Laryngoscopy and Tracheal Intubation. Journal of the Anaesthesiology and Reanimation, 7, 82-87.

[20] Agarwal, A., Gautam, S., Gupta, D., Agarwal, S., Singh, P.K. and Singh, U. (2008) Evaluation of a Single Preoperative Dose of Pregabalin for Attenuation of Postoperative Pain after Laparoscopic Cholecystectomy. British Journal of Anaesthesia, 101, 700-704. https://doi.org/10.1093/bja/aen244

[21] Peng, P.W.H., Li, C., Farcas, E., Haley, A., Wong, W., Bender, J., et al. (2010) Use of Low-Dose Pregabalin in Patients Undergoing Laparoscopic Cholecystectomy. British Journal of Anaesthesia, 105, 155-161. https://doi.org/10.1093/bja/aeq116 
[22] Bahgat, N.M., Sadik, S.A., Mahdy, W.R., El-Sharkawy, O.A., Metwally, A.A. and El-Shafey, M.K. (2016) The Effects of Using Pregabalin versus Clonidine Premedication in Laparoscopic Cholecystectomy. Menoufia Medical Journal, 29, 530-538. https://doi.org/10.4103/1110-2098.198695

[23] Paech, M.J., Goy, R., Chua, S., Scott, K., Christmas, T. and Doherty, D.A. (2007) A randomized, Placebo-Controlled Trial of Preoperative Oral Pregabalin for Postoperative Pain Relief after Minor Gynecological Surgery. Anesthesia \& Analgesia, 105, 1449-1453. https://doi.org/10.1213/01.ane.0000286227.13306.d7

[24] Siddiqui, N.T., Fischer, H., Guerina, L. and Friedman, Z. (2014) Effect of a Preoperative Pregabalin on Postoperative Analgesia in Patients with Inflammatory Bowel Disease Following Major Bowel Surgery: A Randomized, Placebo-Controlled Trial. Pain Practice, 14, 132-139. https://doi.org/10.1111/papr.12058

[25] Park, S.S., Kim, D.-H., Nam, I.-C., Lee, I.-H. and Hwang, J.-W. (2015) The Effectiveness of Pregabalin for Post-Tonsillectomy Pain Control: A Randomized Controlled Trial. PLOS ONE, 10, e0117161.

https://doi.org/10.1371/journal.pone.0117161

[26] Zhang, J., Ho, K.Y. and Wang, Y. (2011) Efficacy of Pregabalin in Acute Postoperative Pain: A Meta-Analysis. British Journal of Anaesthesia, 106, 454-462.

https://doi.org/10.1093/bja/aer027 